\title{
Elevated APOBEC3B expression drives a kataegic-like mutation signature and replication stress-related therapeutic vulnerabilities in p53-defective cells
}

Jenni Nikkilä ${ }^{1}$, Rahul Kumar ${ }^{1}$, James Campbell ${ }^{1}$, Inger Brandsma ${ }^{1}$, Helen N Pemberton ${ }^{1}$, Fredrik Wallberg ${ }^{2}$, Kinga Nagy ${ }^{3,4}$, Ildikó Scheer ${ }^{3,4}$, Beata G Vertessy ${ }^{3}$, Artur A Serebrenik ${ }^{5}$, Valentina Monni ${ }^{5}$, Reuben S Harris ${ }^{5}$, Stephen J Pettitt ${ }^{1}$, Alan Ashworth ${ }^{\star 1,6}$ and Christopher J Lord ${ }^{\star, 1}$

${ }^{1}$ The CRUK Gene Function Laboratory and The Breast Cancer Now Toby Robins Breast Cancer Research Centre, The Institute of Cancer Research, London SW3 6JB, UK; ${ }^{2}$ FACS Facility, The Institute of Cancer Research, London SW3 6JB, UK; ${ }^{3}$ Department of Applied Biotechnology, Budapest University of Technology and Economics, Müegyetem rkp 3, Budapest H-1111, Hungary; ${ }^{4}$ Institute of Enzymology, RCNS, Hungarian Academy of Sciences, Magyar Tudósok Str. 2, Budapest H-1117, Hungary and ${ }^{5}$ Howard Hughes Medical Institute, Department of Biochemistry, Molecular Biology, and Biophysics, University of Minnesota, Minneapolis, Minnesota 55455, USA

Background: Elevated APOBEC3B expression in tumours correlates with a kataegic pattern of localised hypermutation. We assessed the cellular phenotypes associated with high-level APOBEC3B expression and the influence of p53 status on these phenotypes using an isogenic system.

Methods: We used RNA interference of p53 in cells with inducible APOBEC3B and assessed DNA damage response (DDR) biomarkers. The mutational effects of $\mathrm{APOBEC3B}$ were assessed using whole-genome sequencing. In vitro small-molecule inhibitor sensitivity profiling was used to identify candidate therapeutic vulnerabilities.

Results: Although APOBEC3B expression increased the incorporation of genomic uracil, invoked DDR biomarkers and caused cell cycle arrest, inactivation of p53 circumvented APOBEC3B-induced cell cycle arrest without reversing the increase in genomic uracil or DDR biomarkers. The continued expression of APOBEC3B in p53-defective cells not only caused a kataegic mutational signature but also caused hypersensitivity to small-molecule DDR inhibitors (ATR, CHEK1, CHEK2, PARP, WEE1 inhibitors) as well as cisplatin/ATR inhibitor and ATR/PARP inhibitor combinations.

Conclusions: Although loss of p53 might allow tumour cells to tolerate elevated APOBEC3B expression, continued expression of this enzyme might impart a number of therapeutic vulnerabilities upon tumour cells.

The APOBEC (apolipoprotein B editing enzyme catalytic polypeptide-like) family of polynucleotide cytidine deaminase enzymes fulfil various physiological functions in humans, varying from antibody gene diversification to innate immunity (Harris and Liddament, 2004; Conticello, 2008). APOBECs function in innate immunity by deaminating single-stranded DNA (ssDNA) replication intermediates of viral pathogens (retro-, hepadna-, papilloma-viruses), inhibiting the retrotransposition of L1 and Alu elements and mediating the clearance of foreign DNA through deamination-dependent 
mechanisms (Jarmuz et al, 2002; Burns et al, 2015). In addition to these functions in normal physiology, APOBEC enzymes have also been implicated in cancer pathogenesis. The expression levels of several APOBEC enzymes, including APOBEC3B, are altered in tumours (Ding et al, 2011; Nik-Zainal et al, 2012a; Burns et al, 2013a; Alexandrov et al, 2013; Leonard et al, 2013; Henderson et al, 2014; Rebhandl et al, 2014; Saraconi et al, 2014; The Cancer Genome Atlas Research Network, 2014). Upregulation of APOBEC3B in tumours has been associated with localised clusters of strand-specific cytosine to thymine (C-to-T) or cytosine to guanine (C-to-G) mutations (kataegic mutations) that tend to occur within TCW sequence motifs (W = adenine or thymine) and at rearrangement breakpoints (Nik-Zainal et al, 2012a; Roberts et al, 2012; Burns et al, 2013a, b; Drier et al, 2013). This kataegic mutational signature has been identified in multiple cancers, including bladder, breast, cervix, head/neck, thyroid, lung, and several of the blood (Nik-Zainal et al, 2012a; Alexandrov et al, 2013). It seems likely that the ability of APOBEC3B to deaminate cytosine residues to uracil (C-to-U) in ssDNA contributes to this kataegic process (Helleday et al, 2014; Chan and Gordenin, 2015; Swanton et $a l, 2015)$. It has been suggested that APOBEC3B-induced mutagenesis occurs primarily within lagging strand templates arising during DNA replication (Bhagwat et al, 2016; Haradhvala et al, 2016; Hoopes et al, 2016; Seplyarskiy et al, 2016) or on stretches of ssDNA exposed during the resection stage of double-strand break repair or at stalled or collapsed replication forks (Nik-Zainal et al, 2012a; Roberts et al, 2012). The subsequent repair of uracil residues can lead to C-to- $\mathrm{T}$ transition mutations or C-to-G transversions, depending on the DNA repair pathway used to process the uracil lesions (Simonelli et al, 2005; Roberts et al, 2012). Kataegic clustering of C-to-T and C-to-G mutations in the APOBEC3B-preferred TCW motif has been recapitulated in yeast cells expressing human APOBEC3B (Nik-Zainal et al, 2012a; Taylor et al, 2013) and C-to-T mutations accumulate in breast tumour cell lines with upregulated APOBEC3B expression (Burns et al, 2013a; Akre et al, 2016).

The causes of elevated APOBEC3B expression are not fully understood, but it is now established that in human papillomavirus (HPV)-positive cancers of the head/neck and cervix, the HPV E6/E7 oncoprotein causes upregulation of APOBEC3B both at the mRNA and enzymatic activity level (Ohba et al, 2014; Vieira et al, 2014). BK polyomavirus has also been shown to upregulate APOBEC3B in kidney cells, which might explain elevated $A P O B E C 3 B$ levels in urothelial cancers (Verhalen et al, 2016). Furthermore, amplification of the ERBB2 oncogene and loss of PTEN tumour-suppressor function in breast tumours has been proposed to cause replicative stress, which in turn causes an increase in $A P O B E C 3 B$ transcription via an ATR/CHEK1-dependent pathway (Kanu et al, 2016). Finally, the protein kinase $\mathrm{C} / \mathrm{NF}_{\mathrm{K}} \mathrm{B}$ pathway can also induce transcriptional upregulation of $A P O B E C 3 B$ (Leonard et al, 2015).

Here we show that, while induction of APOBEC3B expression elicits a DNA damage response (DDR) and $\mathrm{G}_{2} / \mathrm{M}$ cell cycle arrest, the cell cycle arrest can be abrogated by loss of p53 function, formally identifying p53 dysfunction as a molecular route by which tumour cells might tolerate APOBEC3B activity. Using whole-genome sequencing (WGS), we also show that, in p53-defective cells, APOBEC3B expression drives an increase in the genomic uracil load and causes kataegiclike mutational signatures. Finally, we show that high-level APOBEC3B expression causes hypersensitivity to smallmolecule inhibitors that target the DDR, suggesting that APOBEC3B overexpression can impart targetable vulnerabilities upon cells.

\section{MATERIALS AND METHODS}

Cell lines. 293-A3B and 293-GFP cell lines have been previously described (Akre et al, 2016). Parental 293-A3B cells were infected with GIPZ TP53 shRNA lentivirus (Dharmacon, GE Healthcare, Little Chalfont, UK) to generate constitutive silencing of TP53 mRNA in the cells. Seventy-two hours after viral infection, cells were selected in $1 \mu \mathrm{g} \mathrm{ml}^{-1}$ puromycin to remove non-transduced cells, and clones were isolated after single-cell sorting with $\mathrm{BD}$ FACSAria II SORP (BD Biosciences, San Jose, CA, USA).

CRISPR/Cas9-mediated gene knockout. A single guide RNA (sgRNA) was designed to target the 5'-ACTTCCTGAAAACAACGTTC- $3^{\prime}$ site in exon 3 of TP53 (Supplementary Figures S3B-E). The sgRNA was ligated into a lentiviral CRISPR vector, which allows for dual expression of the sgRNA and Cas9 endonuclease using the protocol from the Zhang Laboratory (Sanjana et al, 2014). This construct was cloned by annealing oligos $5^{\prime}$-CACCGACTTCCTGAAAACAACGTTC- $3^{\prime}$ and 5'-GAACGAACGTTGTTTTCAGGAAGTC- $3^{\prime}$. This vector was used to produce transducing virus and create a $293-\mathrm{A} 3 \mathrm{~B}-\Delta \mathrm{p} 53$ clone following a previously described protocol (Anderson and Harris, 2015).

Clonogenic survival assay. 293-A3B and 293-A3B- $\Delta$ p53 cells were seeded into six-well plates (500 cells per well) (Supplementary Figures S3C and D). The cells were treated with either mock $\left(\mathrm{H}_{2} \mathrm{O}\right)$ or doxycycline (dox; $1 \mu \mathrm{g} \mathrm{ml}^{-1}$ ) $8 \mathrm{~h}$ after plating. Once colonies of $>50$ cells formed in the 293-A3B mock-treated wells ( $\sim 9$ days), the plates were washed with PBS and stained with $50 \%$ methanol and $0.5 \%$ crystal violet, and the colonies were counted by hand.

Western blotting. Cells were collected, washed with PBS and resuspended in lysis buffer containing $1 \mathrm{mM}$ sodium vanadate, $20 \mathrm{mM}$ sodium fluoride, 1\% Igepal CA-630, 0.0225\% Triton X, $1 \times$ cOmplete ULTRA EDTA-free protease inhibitor cocktail tablet (Roche, Welwyn Garden City, UK) and $1 \times$ PhosSTOP phosphatase inhibitor cocktail tablet (Roche). To enhance cell lysis, sonication was used. The insoluble fraction was removed by centrifugation. Protein concentration was measured with Bio-Rad Protein Assay (Bio-Rad, Cambridge, UK) to ensure equivalent total protein load per lane. Proteins were denatured by boiling for $10 \mathrm{~min}$ and resolved under reducing conditions on $4-12 \%$ Bis-Tris gels (NuPAGE, Thermo Fisher Scientific, Paisley, UK). Proteins were transferred to nitrocellulose membrane (Amersham Protran, GE Healthcare, Little Chalfont, UK). Membranes were blocked with either $5 \%(\mathrm{w} / \mathrm{v})$ non-fat dried milk or mixture of $1 \%(\mathrm{w} / \mathrm{v})$ non-fat dried milk and $1 \%(\mathrm{w} / \mathrm{v})$ bovine serum albumin. Primary antibodies used were: $\gamma \mathrm{H} 2 \mathrm{AX}$ (Ser139, Cell Signaling, Danvers, MA, USA; used at 1:3000 (v/v) dilution), pRPA32 (S4/S8, Bethyl Laboratories, Montgomery, TX, USA; $1: 1000)$, APOBEC3B (521087-13, (Leonard et al, 2015), $1: 1000$ and Abcam, Cambridge, UK; $1: 5000$ ), GFP (Cell Signaling, 1:5000), pCHK1 (Ser345, Cell Signaling, $1: 1000$ ), pCHK2 (Thr68, Cell Signaling, $1: 1000)$, CHK1 (Santa Cruz, Santa Cruz, CA, USA $1: 1000$ ), CHK2 (Cell Signaling, $1: 1000)$, PARP1 (Santa Cruz, 1:1000), p-p53 (Ser15, Cell Signaling, 1:1000), p53 (DO-I clone, Sigma, 1:1000), RPA1 (RPA-70, Abcam, 1:1000), Histone H3 (Cell Signaling, $1: 1000)$, Actin (Sigma, Poole, UK; $1: 10000)$, or $\beta$-tubulin $(1: 10000$, Sigma). After applying horseradish peroxidase-coupled secondary antibodies (Amersham Pharmacia Biotech, Little Chalfont, UK), immunoreactive bands were visualised by ECL chemiluminescence reagent (Novex, Thermo Fisher Scientific, Little Chalfont, UK), and images were developed onto Amersham Hyperfilm (GE Healthcare, Little Chalfont, UK). Expression levels were quantified by using the Image J 1.50i software (NIH, Bethesda, MD, USA). In Supplementary Figure S3B, cells were collected, washed with PBS, 
and resuspended in $100 \mathrm{ml}$ reducing sample buffer per one million cells $(0.5 \mathrm{M}$ Tris- $\mathrm{HCl} \mathrm{pH} 6.8,1 \%$ 2-mercaptoethanol, $10 \%$ sodium dodecyl sulfate, $50 \%$ glycerol). Proteins were denatured by boiling samples for $20 \mathrm{~min}$, and resolved by SDS-polyacrylamide gel electrophoresis. Proteins were transferred to a PVDF-FL membrane (Millipore, Watford, UK) and blocked in 5\% milk in phosphate-buffered saline (PBS). Primary antibodies were incubated in PBS.0.1\% Tween 20, and secondary antibodies were incubated in PBS.0.1\% Tween 20.0.2\% SDS. The membrane was imaged using a LI-COR Odyssey instrument. The primary antibodies used were: p53 (DO-1 clone, Santa Cruz, 1:1000) and b-actin (Cell Signaling, $1: 2000)$. The secondary antibodies used were: IRDye $800 \mathrm{CW}$ goat anti-rabbit (LI-COR, Cambridge, UK; $1: 10$ 000) and Alexa Fluor 680 goat anti-mouse (Molecular Probes, Paisley, UK, $1: 10$ 000).

Uracil incorporation assay. DNA was purified using the MasterPure Complete DNA and RNA Purification Kit and the DNA Clean \& Concentrator-5 Kit (Zymo Research, Irvine, CA, USA) from 292-A3B and 293-A3B-p53 cells exposed to 100 and $1000 \mathrm{ng} \mathrm{ml}^{-1} \mathrm{ml}^{-1}$ dox $(72 \mathrm{~h})$. DNA was prepared according to the manufacturer's instructions. Uracil quantifications for the 293A3B and 293-A3B-p53 DNA samples were performed as in described in Rona et al (2016).

Cell cycle analysis. 293-A3B and 293-A3B-p53 cells were either exposed to 0 or $100 \mathrm{ng} \mathrm{ml}^{-1}$ dox for $48 \mathrm{~h}$ before fixing in $70 \%(\mathrm{v} / \mathrm{v})$ EtOH. Cells were stained for DNA synthesis using the Click-iT EdU Alexa Fluor 647 Flow Cytometer Assay Kit (Molecular Probes, Thermo Fisher Scientific, Loughborough, UK), according to the manufacturer's protocol. In addition, the cells were stained with anti-phospho-Histone H3 (Ser10) antibody that specifically recognises $M$ phase cells ( $1: 200$, Merck Millipore, Watford, UK). Fluorescence labeling was done with a Per-CP conjugated antibody $(1: 30$, Stratech, Newmarket, UK). The nucleotide analogue 5ethynyl-2'-deoxyuridine (EdU) was conjugated with Alexa Fluor 647 azide and DNA content was measured by addition of $4^{\prime}, 6$ diamino-2-phenylindole (DAPI, 1:10000, Molecular Probes, Thermo Fisher Scientific). Measurements took place on a BD LSR II SORP flow cytometer (BD Biosciences) equipped with a $404 \mathrm{~nm}$ violet laser, a $488 \mathrm{~nm}$ blue laser and a $633 \mathrm{~nm}$ red laser. Cell population was gated in a FSC/SSC dot plot and doublets were gated out based on a DAPI area/width dot plot. The single-cell populations were further analysed regarding its cell distribution. G1, S and $\mathrm{G}_{2} / \mathrm{M}$ phase cell populations were defined in a DAPI/ EdU-Alexa Fluor 647 dot plot and $\mathrm{G}_{2} / \mathrm{M}$ phase cells were further separated in a DAPI/Per-CP dot plot. For quantification, BD FACSDiva software (BD Biosciences) was used.

Whole-genome sequencing. 293-A3B-p53 cells were exposed to either 0 or $1000 \mathrm{ng} \mathrm{ml}^{-1}$ dox for 14 days followed by single-cell sorting with BD FACSAria III (BD Biosciences). Clones were expanded in normal growth media. DNA from pelleted cells was isolated using the Puregene Cell and Tissue DNA Isolation Kit (Qiagen, Manchester, UK) and WGS of DNA samples was performed by the Beijing Genome Institute (BGI). Libraries were sequenced using a HiSeq X Ten sequencer (Illumina, San Diego, CA, USA), acquiring approximately 600 million $150 \mathrm{bp}$ paired-end reads per sample. Sequences were aligned to the human reference genome (GRCh37) using bwa-mem (http://arxiv.org/abs/ 1303.3997). PCR duplicates were removed prior to further processing and variant detection. Median depth of coverage ranged from 27 reads to 32 reads and $>97.9 \%$ of the mappable genome was covered by five reads or more. Base quality recalibration and realignment was performed using the GATK (v3) (https://software.broadinstitute.org/gatk/). Mutation calling was performed using Mutect (https://software.broadinstitute.org/ gatk/). Data were deposited on NCBI Short Read Archive (http://
www.ncbi.nlm.nih.gov/Traces/sra/sra.cgi) using the accession number SRP090739.

Small-molecule inhibitor assays. 293-A3B-p53 cells were plated on six-well plates (500 cells per well) $24 \mathrm{~h}$ before starting smallmolecule inhibitor exposure and inducing APOBEC3B with dox. Medium containing 0 or $1000 \mathrm{ng} \mathrm{ml}^{-1}$ dox was added with inhibitors. Small-molecule inhibitors were supplied by Selleckchem, Munich, Germany, with the exception of CCT241533 (Tocris Bioscience, Bristol, UK), SAR020106 (the kind gift of Professor Ian Collins, ICR) and cisplatin (Sigma). Inhibitors and dox-containing media was changed every 3 days, and cell viability was estimated after 14 days using CellTiter-Glo reagent (Promega, Madison, WI, USA).

RT-qPCR analysis. RNA was isolated using Qiagen RNeasy Mini Kit (Qiagen, Manchester, UK) according to the manufacturer's instructions, and cDNA was generated by reverse transcription reaction using the Omniscript Kit (Qiagen) according to the manufacturer's instructions. TaqMan gene expression assay was used to analyse relative $A P O B E C 3 B$ mRNA expression levels. $A P O B E C 3 B$ expression was normalised to GAPDH mRNA expression (Applied Biosystems, ThermoFisher Scientific, Loughborough, UK).

Statistical analysis. Two-sided $t$-test was used for single inhibitor tests and two-way ANOVA for the dose/response curves. Statistics were calculated using GraphPad Prism version 6.00 for Mac OS X (GraphPad Software, La Jolla, CA, USA; http:// www.graphpad.com).

\section{RESULTS}

Inactivation of TP53 abrogates the cell cycle checkpoints elicited by APOBEC3B expression. To explore the molecular phenotypes associated with elevated APOBEC3B expression, we used human (HEK) 293 cells encompassing a chromosomally integrated doxinducible APOBEC3B-GFP fusion cDNA construct (293-A3B cells (Akre et al, 2016)). Consistent with previous reports (Burns et al, 2013a; Lackey et al, 2013; Taylor et al, 2013; Akre et al, 2016), we found that APOBEC3B expression caused induction of a DDR characterised by $\gamma \mathrm{H} 2 \mathrm{AX}$ and RPA phosphorylation, biomarkers of replication fork stress, which was absent from doxexposed 293-GFP cells lacking APOBEC3B construct (Figure 1A). We also noted increased levels of CHEK2 Thr68 phosphorylation normally associated with the $\mathrm{G}_{2} / \mathrm{M}$ cell cycle checkpoint (Reinhardt and Yaffe, 2009), as well as CHEK1 Ser345 phosphorylation upon induction of APOBEC3B expression (Supplementary Figures S1, S2A and B). Consistent with these observations, we found that induction of $\mathrm{APOBEC} 3 \mathrm{~B}$ reduced EdU incorporation (Figure 1B; 10.6\% EdU-negative cells in APOBEC3B-positive cells $v s \quad 1.8 \%$ in EdU-negative cells), suggesting that replication in $S$ phase was impaired. Overexpression of APOBEC $3 B$ also resulted in $\mathrm{G}_{2} / \mathrm{M}$ cell cycle arrest (Figure 1B); in the absence of APOBEC3B 7.6\% of cells were in $\mathrm{G}_{2}$ cells and $1.4 \%$ in $\mathrm{M}$ phase, while the expression of APOBEC3B caused these proportions to rise to $21 \%\left(\mathrm{G}_{2}\right)$ and $5.7 \%$ (M phase) (Figure 1B). This induction of APOBEC3B expression also impaired the proliferative capacity of cells (Figure 1C).

DDR often results in the induction of p53 activity and apoptosis (Lakin et al, 1999; Tibbetts et al, 1999). We found that APOBEC3B induction in 293-A3B cells led to elevated p53 levels and increased phosphorylation of p53 at residue Ser15 and PARP1 cleavage, indicative of an apoptotic response (Kaufmann et al, 1993) (Figure 1D, Supplementary Figures S2C and D). To assess whether inhibition of cell proliferation caused by APOBEC3B expression was mediated by $\mathrm{p} 53$ activity, we depleted 
A

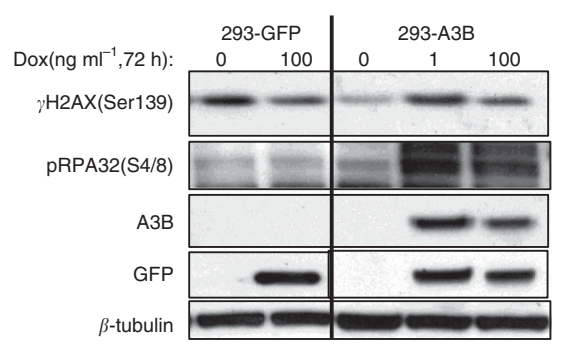

C $\quad-293-A 3 B$ DOX $\left(1000 \mathrm{ng} \mathrm{m}^{-1}\right)$

$\rightarrow$ 293-A3B DMSO

$\rightarrow$ 293-A3B-p53 DMSO

- 293-A3B-p53 DOX (100 $\left.\mathrm{ng} \mathrm{ml}^{-1}\right)$

- 293-A3B-p53 DOX (1000 $\left.\mathrm{ng} \mathrm{ml}^{-1}\right)$

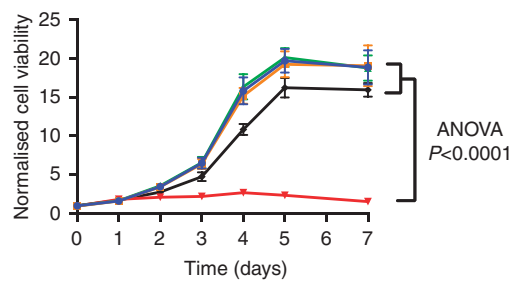

E

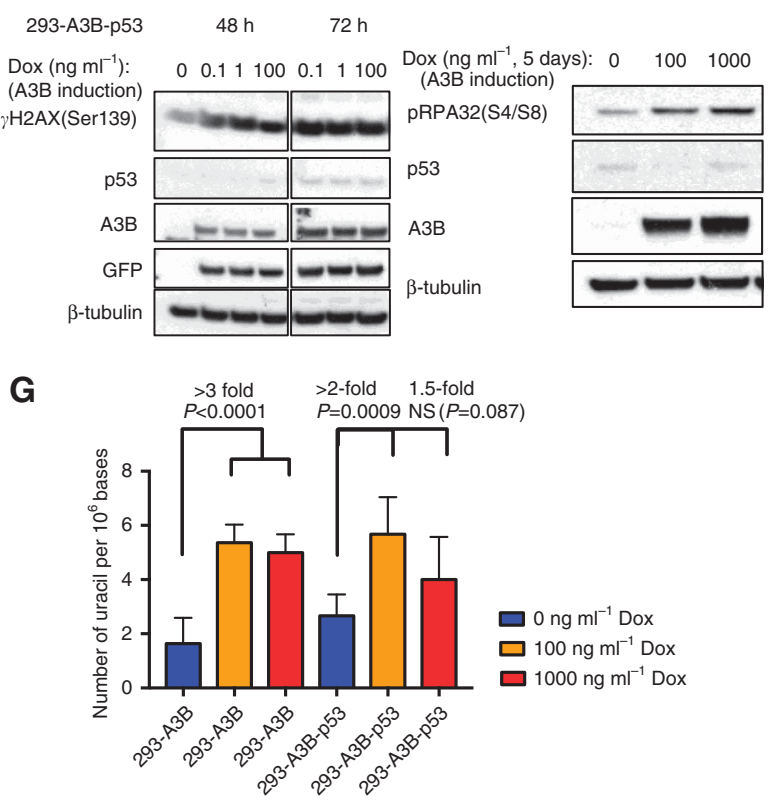

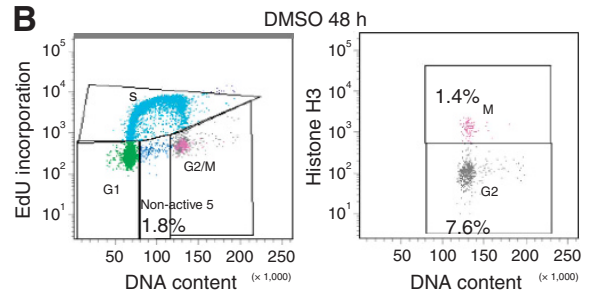
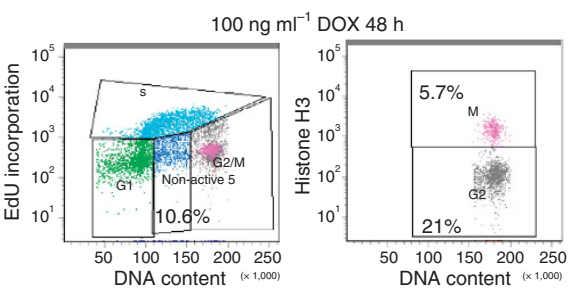

D

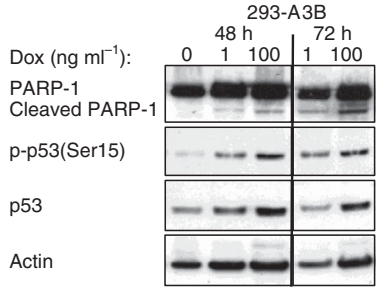

$\mathbf{F}$

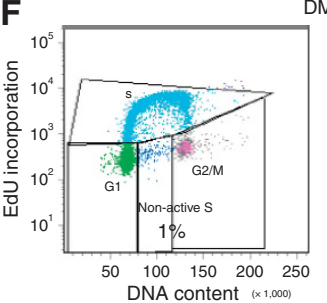

DMSO $48 \mathrm{~h}$
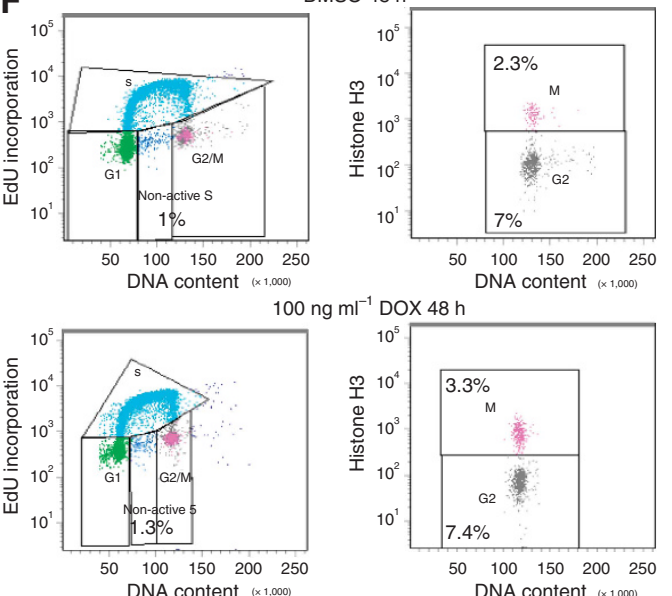

$00 \mathrm{ng} \mathrm{ml}^{-1}$ DOX $48 \mathrm{~h}$

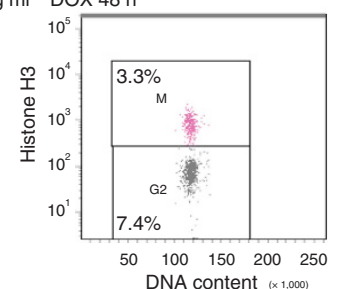

Figure 1. TP53 silencing abrogates APOBEC3B-induced cell cycle arrest and cell death. (A) Induced APOBEC3B expression results in elevated phosphorylation of $\gamma \mathrm{H} 2 \mathrm{AX}$ (Ser139) and RPA32(S4/8) in 293-A3B cells. 293-GFP cells were included as a negative control and express GFP but not APOBEC3B upon dox exposure. (B) Induced APOBEC3B expression results in replication stress and arrests cells in $G_{2} / M$ phase. $F A C S$ profiles in cells labelled with EdU (left panels) or anti-phospho histone $\mathrm{H} 3$ antibody ('histone $\mathrm{H} 3$ ', right panels) are shown. Fraction (\%) of cells in non-active $\mathrm{S}$ phase are shown in the left-hand panels. Fraction (\%) of anti-phospho histone $\mathrm{H} 3+$ ve and - ve cells are shown in the right-hand panels. (C) APOBEC3B induction drives cell inhibition in vitro, which can be rescued by TP53 silencing. Growth curves of 293-A3B and 293-A3B-p53 cells treated with DMSO and 100 or $1000 \mathrm{ng} \mathrm{ml}^{-1}$ of dox, was measured using CellTiter-Glo reagent are shown. Cell growth was analysed on the indicated day after inducing APOBEC3B-GFP expression. Each data point represents eight replicates. Two-way ANOVA was used to calculate $P$-values. Error bars indicate s.d. for each measured group. (D) Induced APOBEC3B expression activates the apoptotic pathway. APOBEC3B induction results in an increase in cleaved PARP1 and phosphorylated p53 on Ser15 levels 48-72 h after dox induction in 293-A3B cells as shown by western blotting. (E) TP53 silencing abolishes p53 expression while maintaining inducible APOBEC3B and GFP expression, leading to elevated phosphorylation of H2AX (Ser139, $\gamma \mathrm{H} 2 \mathrm{AX}$ ) and RPA32 (S4/8) in 293-A3B-p53 cells 48-72 h and also 5 days after inducing APOBEC3B with $0.1-1000 \mathrm{ng} \mathrm{ml}^{-1}$ of dox. (F) TP53 silencing alleviates APOBEC3B-driven replication stress and $\mathrm{G}_{2} / \mathrm{M}$ arrest in $293-A 3 B-p 53$ cells as shown by FACS profiling. Legend as per panel (B). (G) APOBEC3B-GFP induction increases genomic uracil $(P=0.0009)$ in 293-A3B-p53 cells when compared with non-induced 293-A3B-p53 cells. Each data point represents the mean of at least six replicates. A two-sided Student's t-test was used to estimate statistical significance. Error bars indicate s.d. for each measured groups. Method described in (Rona et al, 2016). In panels (A, B and D), APOBEC3B was induced with 1 and $100 \mathrm{ng} \mathrm{ml}^{-1}$ of dox for 48 or $72 \mathrm{~h}$, DMSO was used as control $\left(0 \mathrm{ng} \mathrm{ml} \mathrm{m}^{-1}\right)$. 
A

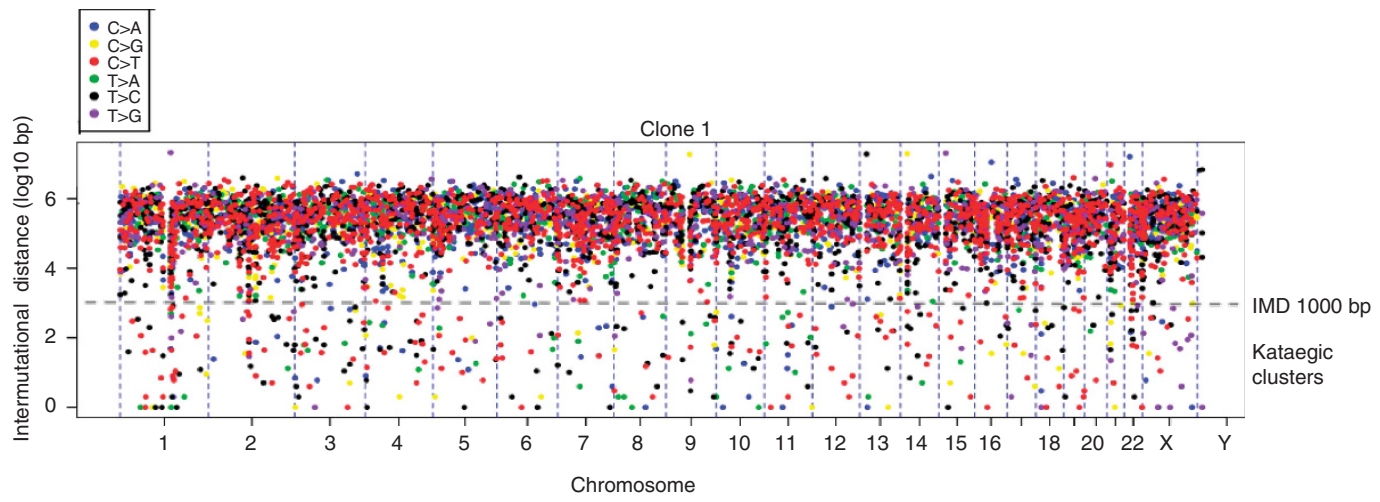

B

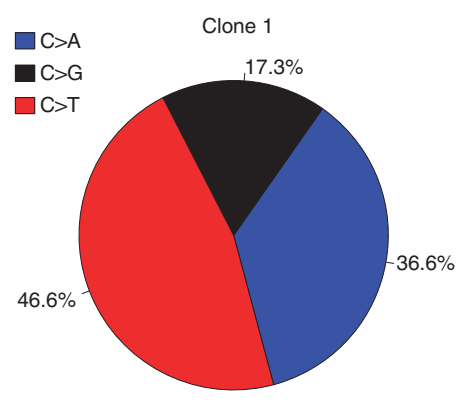

D

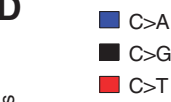

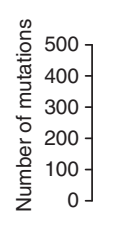

$\mathrm{C}>\mathrm{T}$

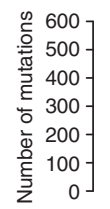

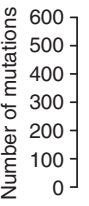

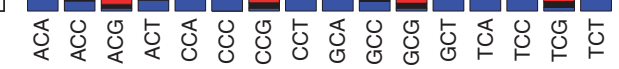

C

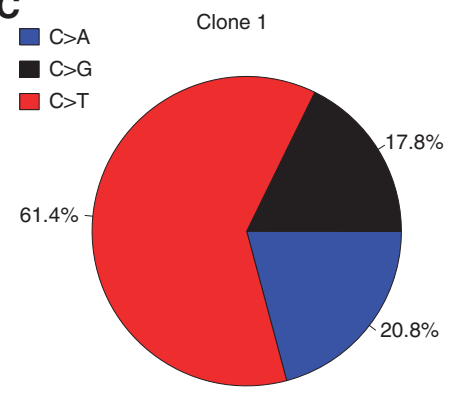

Figure 2. Induced $A$ POBЕС $3 B$ expression drives a kataegis-like mutation signature and leads to an increase in overall C-to-T mutation load in the TCW sequence context. (A) APOBEC3B induction causes genome-wide mutation clustering that was present only in dox-treated 293-A3B-p53 cells. Mutation clusters were measured by their IMD (upper panel). Each dot represents one mutation. y Axis represents intermutation distance, that is, the genomic distance of each mutation from the previous one. $x$ Axis represents position in human genome. The horizontal line (1000 bp) shows the cutoff for mutations with IMD $\leq 1000 \mathrm{bp}$. (B) Cytosine mutations present only in dox-treated 293-A3B-p53 cells (clone 1) were mainly C-to-T transitions (red). (C) Cytosine mutations in kataegic clusters (mutations with IMD $\leq 1000$ bp) were mostly C-to-T transitions (red). (D) Cytosine (C-to-G and C-to-A) mutations in dox-treated 293-A3B-p53 cells were enriched in TCW trinucleotide contexts (marked with asterisk). Panels (A-C) show clone 1 as an example; other clones shown in Supplementary Figure S5.

p53 in 293-A3B cells using constitutively expressed shRNA, generating a 293-A3B-p53 clone. In 293-A3B-p53 cells, the induction of APOBEC3B did not cause a proliferative defect, as it did in cells expressing p53 (Figure 1C), but still caused a DDR, as measured by induction of $\gamma \mathrm{H} 2 \mathrm{AX}$ and phosphorylation of RPA (Figure 1E). The level of APOBEC3B and $\gamma \mathrm{H} 2 \mathrm{AX}$ expression induction was similar over a range of concentrations of dox used (10-1000 $\mathrm{ng} \mathrm{ml}^{-1}$ of dox, Supplementary Figure S3A). We also found that inactivation of p53 in 293-A3B cells, via CRISPRCas9-mediated mutagenesis, also reversed the proliferative defect caused by APOBEC3B induction (Supplementary Figures S3B-E), confirming the observations made in 293-A3B-p53 cells. Consistent with the absence of a proliferative defect, APOBEC3B expression in 293-A3B-p53 cells did not induce $G_{2} / M$ arrest
(Figure 1F). However, we found that induction of APOBEC3B expression caused similar levels of uracil incorporation into genomic DNA in 293-A3B and 293-A3B-p53 cells (Figure 1G), suggesting that the failure to observe cell cycle arrest in 293-A3Bp53 cells was not due to reduced APOBEC3B activity. Taken together, this data formally demonstrated that loss of p53 function allows cells to tolerate elevated APOBEC3B expression in the face of an on-going DDR.

APOBEC3B expression increases APOBEC signature mutations and a kataegis-like process in p53-defective cells. 293-A3B-p53 cells continued to proliferate in the presence of high-level APOBEC3B expression, despite displaying elevated levels of genomic uracil incorporation and on-going activation of DDR 
A
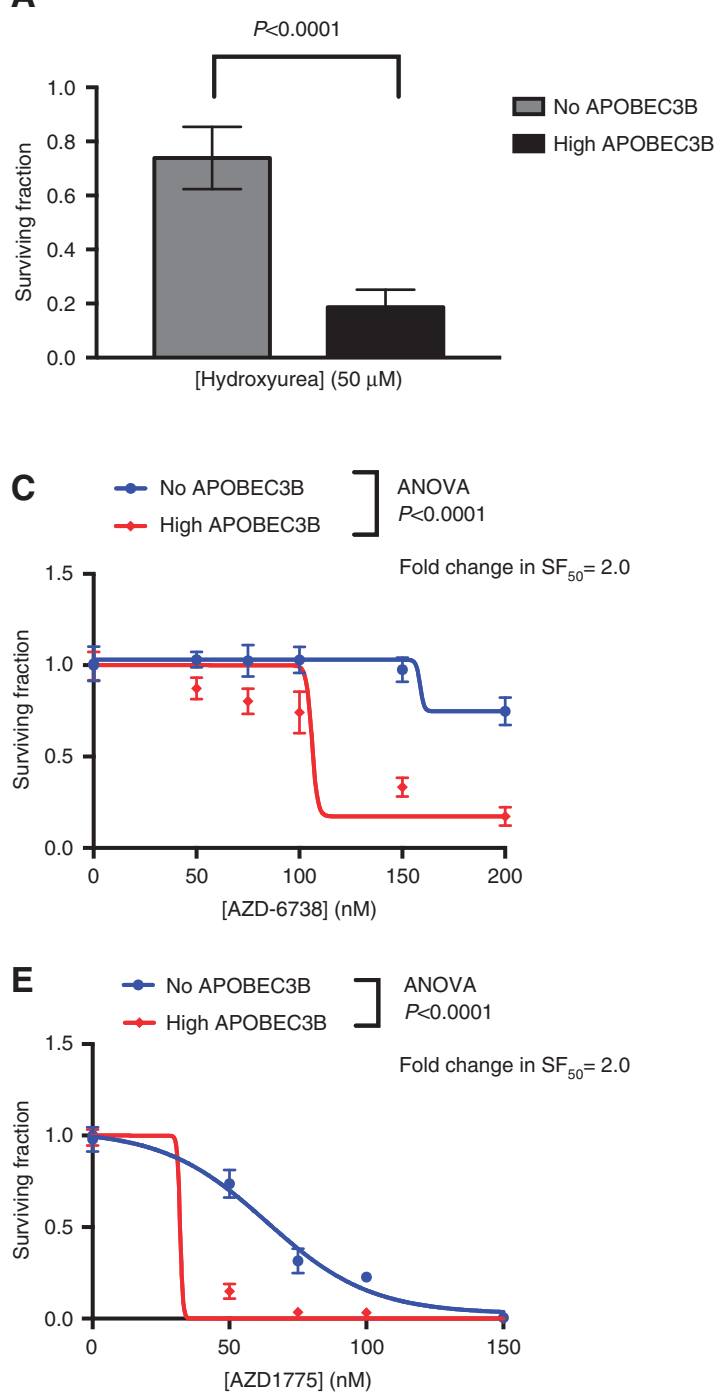

B
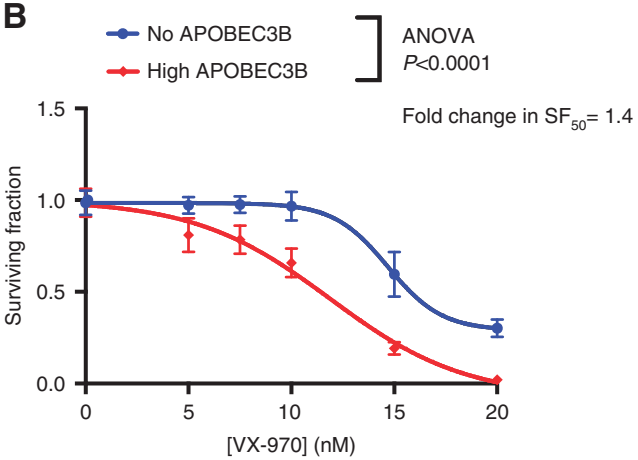

D
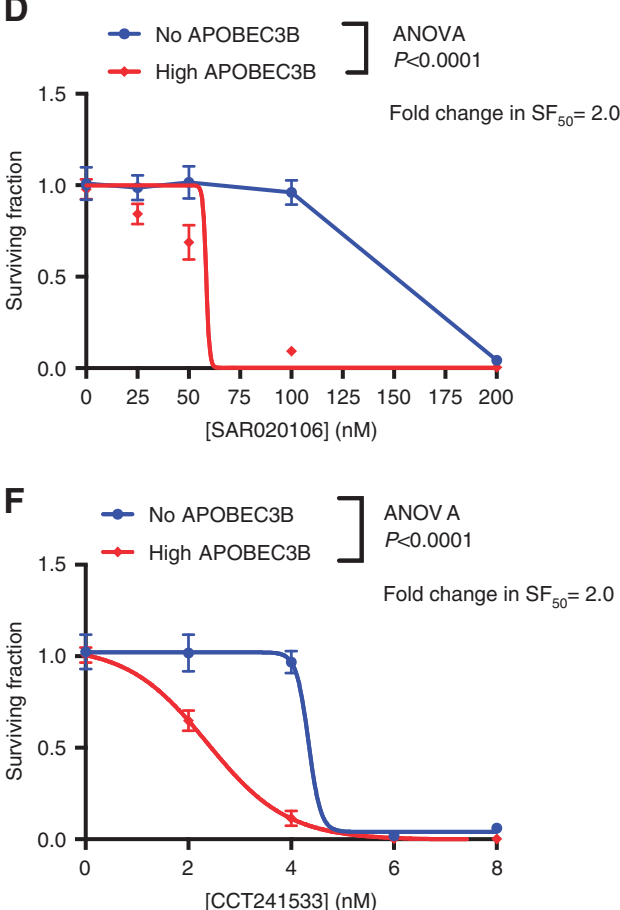

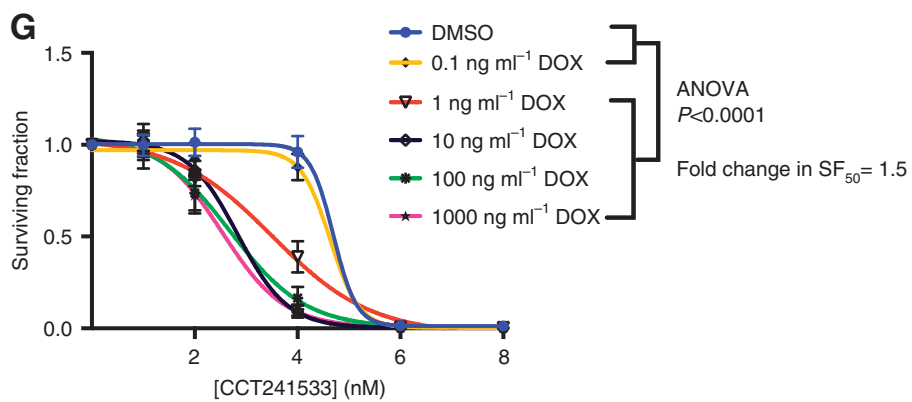

Figure 3. APOBEC3B expression sensitizes cells to inhibitors targeting DDR-related kinases. APOBEC3B induction in 293-A3B-p53 cells causes sensitivity to: (A) $50 \mu \mathrm{M} \mathrm{HU}$ (Student's t-test, $P<0.0001$ ), (B) the ATR inhibitor VX-970 (ANOVA, $P<0.0001$ ), (C) the ATR inhibitor AZD6738 (ANOVA, $P<0.0001$ ), (D) the CHEK1 inhibitor SAR020106 (ANOVA, $P<0.0001$ ), (E) the WEE1 inhibitor AZD1775 (ANOVA, $P<0.0001$ ), and $(\mathbf{F}$ and $\mathbf{G}$ ) the CHEK2 inhibitor CCT241533 (ANOVA, $P<0.0001$ ). In panels $(\mathbf{A}-\mathbf{F})$, 14-day inhibitor exposures were used with or without $1000 \mathrm{ng} \mathrm{ml}^{-1}$ dox to induce APOBEC3B. In panel (G), the indicated concentrations were used. Cell viability was assessed using CellTiter-Glo reagent at the end of each treatment course. Each data point represents the mean of three replicates. Error bars represent s.d.

biomarkers. This led us to assess whether APOBEC3B expression in p53-defective cells would ultimately lead to a kataegis-like DNA mutational pattern. To do this, we exposed 293-A3B-p53 cells to $1000 \mathrm{ng} \mathrm{ml}^{-1}$ of dox for 14 continuous days to chronically upregulate APOBEC3B and then isolated three individual subclones (clones 1-3) from single cells as well as a control subclone isolated from 293-A3B-p53 cells cultured for 14 days in the absence of dox/APOBEC3B induction (control clone). Each of these clones was subjected to WGS (average depth of $30 \times$ ). The genomic sequence in the control clone was used as the reference genome. Using these data, we identified mutations that had arisen in 293-A3B-p53 clones 1-3 but were absent in the control clone; variant calls for clones 1-3 are presented in Supplementary Tables S1-S3. We then estimated the extent of kataegis by calculating intermutational distances (IMD; Nik-Zainal et al, 2012a) for each clone, illustrating this data as rainfall plots (Figure $2 \mathrm{~A}$ and 

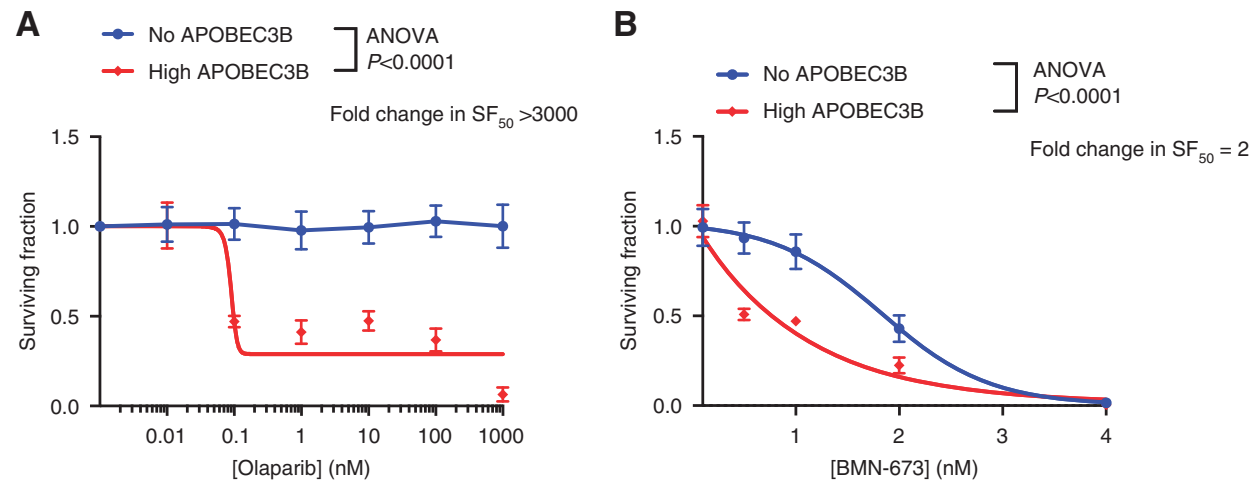

Figure 4. APOBEC3B expression sensitizes cells to PARP inhibitors. APOBEC3B induction in 293-A3B-p53 cells causes sensitivity to the clinical PARP inhibitors, olaparib (A, ANOVA, $P<0.0001$ ) and (B) BMN-673 (ANOVA, $P<0.0001$ ). Fourteen-day inhibitor exposures were used with or without $1000 \mathrm{ng} \mathrm{ml}^{-1}$ dox to induced APOBEC3B. Cell viability was assessed using CellTiter-Glo reagent at the end of each treatment course. Each data point represents the mean of three replicates. Error bars represent s.d.

A

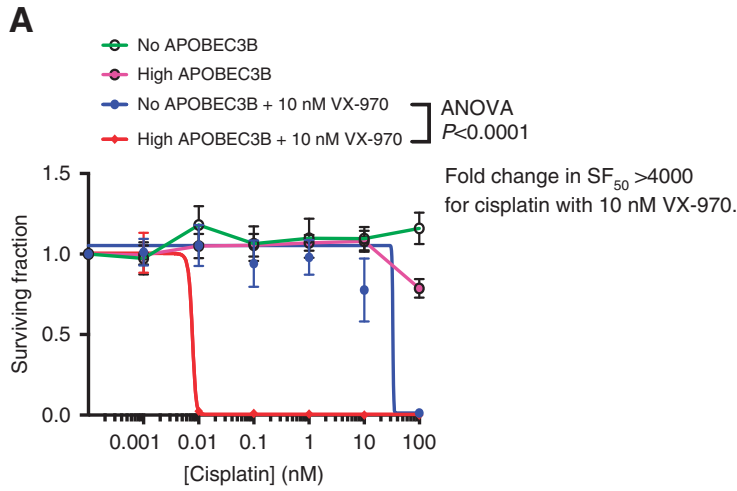

C

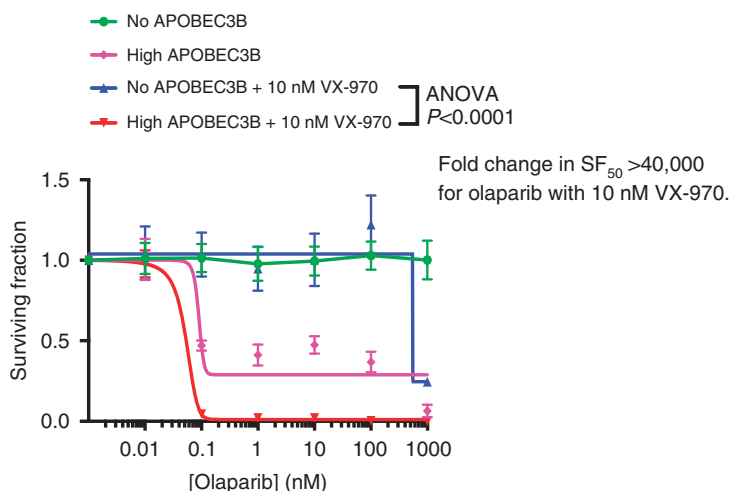

B $\rightarrow$ No АРОВЕСЗВ

๑- High АРОВEC3B

$\rightarrow$ No APOBEC3B + 100 nM AZ20 7 ANOVA

$\rightarrow$ High APOBEC $3 B+100 \mathrm{nM}$ AZ20 $\rightarrow P<0.0001$

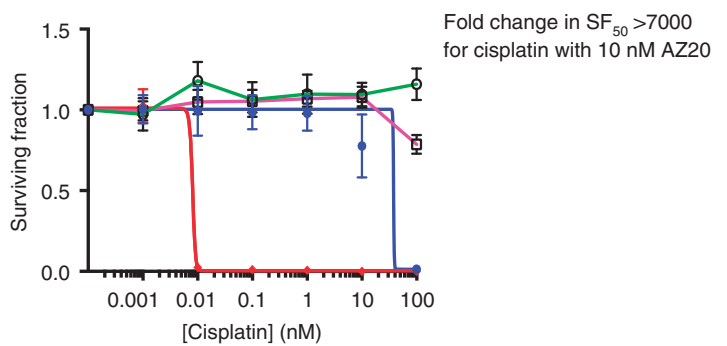

D $\rightarrow$ NO APOBEC3B

$\rightarrow$ High АРОВЕСЗВ

$=$ No APOBEC3B + $10 \mathrm{nM}$ Olaparib

$=$ High APOBEC $3 B$ + $10 \mathrm{nM}$ Olaparib

- No APOBEC3B + $100 \mathrm{nM}$ Olaparib

- High АРОВЕС $3 \mathrm{~B}+100 \mathrm{nM}$ Olaparib $] \begin{aligned} & \text { ANOVA } \\ & P<0.000\end{aligned}$

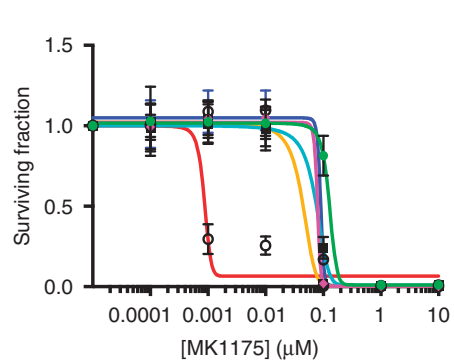

Fold change in $\mathrm{SF}_{50}=148$ for AZD1775 with $100 \mathrm{nM}$ VX-970.

Figure 5. APOBEC3B induction in 293-A3B-p53 cells causes sensitivity to DDR inhibitor combinations. (A and B) ATR inhibitors (VX-970, $10 \mathrm{nM}$ and $A Z 20,100 \mathrm{nM}$ ) potentiate the sensitivity of cisplatin in the presence of APOBEC3B induction (ANOVA, $P<0.0001$ as shown). (C) ATR inhibitor $(10 \mathrm{nM})$ potentiates the sensitivity of olaparib $(0-1000 \mathrm{nM})$ in the presence of APOBEC3B induction (ANOVA, $P<0.0001$ as shown). (D) Olaparib $(100 \mathrm{nM})$ potentiates the sensitivity of WEE1 inhibitor in the presence of APOBEC3B induction (ANOVA, $P<0.0001$ as shown). Fourteen-day inhibitor exposures were used with or without $1000 \mathrm{ng} \mathrm{ml}^{-1}$ dox to induce APOBEC3B. Cell viability was assessed using CellTiter-Glo reagent at the end of each treatment course. Each data point represents the mean of three replicates. Error bars represent s.d.

Supplementary Figure S4). A computational definition of a kataegic mutational cluster is where six or more consecutive mutations occur with an IMD of $\leq 1000 \mathrm{bp}$ (Nik-Zainal et al, 2012b). Our IMD analysis identified a kataegic-like signature in all three clones derived from long-term APOBEC3B expression, when compared with the control clone (Figure 2A, Supplementary Figure S4). In general, we observed an average ninefold increase in kataegic mutational clusters in clones 1-3 when compared with the control clone. Altogether 348-422 kataegic events (IMD $\leq 1000 \mathrm{bp}$ ) with mean IMD $155.50-175.34$ bp were analysed for clones 1-3 (clone 1: 369 events with mean IMD $155.50 \mathrm{bp}$; clone 2: 348 events with mean IMD $175.34 \mathrm{bp}$; clone 3: 422 events with mean IMD $166.17 \mathrm{bp})$. These kataegic mutations represented $4.6-5.6 \%$ of all mutated cytosines. The most frequent cytosine mutation events in clones 1-3 were C-to- $\mathrm{T}$ transitions ( $>45 \%$ in Figure $2 \mathrm{~B}$; Supplementary Figure S5A) characteristic of APOBEC3B overexpression. This was more pronounced in kataegic mutational clusters, (IMD $\leq 1000 \mathrm{bp}$ ) where $>57 \%$ of the mutated cytosines were C-to- $\mathrm{T}$ transitions (Figure 2C; Supplementary Figures S5B and S6). 
We also noted that chronic APOBEC3B expression in 293-A3Bp53 cells resulted in enrichment of cytosine mutations in the APOBEC3B-preferred TCG motif (Burns et al, 2013a; Burns et al, 2013b; Leonard et al, 2013) and kataegic TCW trinucleotide motif (Nik-Zainal et al, 2012a). Surprisingly, an enrichment of C-to-A mutations in these motifs was also seen. This is not characteristic of APOBEC3B-induced mutations and could be explained by other mutational processes occurring, such as transcription-coupled nucleotide excision repair, which has been associated with mutational signatures dominated by C-to-A mutations (Alexandrov et al, 2013). It is therefore possible that other mutational processes are active in the APOBEC3B-induced 293A3B-p53 cells. Most of the mutated cytosines in clones 1-3 were C-to- $\mathrm{T}$ transitions (45.4-46.6\% of C-to- $\mathrm{T}$ mutations compared with $35.2-36.1 \%$ of C-to-A and $17.3-18.8 \%$ of C-to-G mutations; Figure 2B, Supplementary Figure S5A) enriched in TCG motifs, a characteristic of APOBEC-mediated mutagenesis (Fisher's exact test for mutated cytosines in TCG context: clone $1, P=1.1 \times 10^{-3}$, $\mathrm{OR}=2.42$; clone $2, P=1.0 \times 10^{-7}$, $\mathrm{OR}=3.31$; clone $3 P=9.0$ $\times 10^{-5}, \mathrm{OR}=2.28$ ). Furthermore, $\mathrm{C}-$ to-G and $\mathrm{C}$-to-A mutations were enriched in kataegic TCW trinucleotides (Fisher's exact test for mutated cytosines in TCW motif: C-to-A, $P=4.70 \times 10^{-9}$ $5.57 \times 10^{-13}$; C-to-G, $\quad P=3.65 \times 10^{-4}-8.95 \times 10^{-8}$; C-to-T $P=1.00$ for all DOX1-3; Figure 2D, Supplementary Figure S7 and Supplementary Table S4). Taken together, our data suggested that prolonged $\mathrm{APOBEC} 3 \mathrm{~B}$ expression in p53-defective cells results in a kataegic-like mutational signature.

APOBEC3B expression sensitises cells to small-molecule DDR inhibitors. Although inactivation of p53 allowed cells to tolerate APOBEC3B expression, we hypothesised that the ongoing DDR caused by APOBEC3B (Figure 1E) might make cells vulnerable to small-molecule inhibitors that further perturb replication or inhibit processes connected to DNA repair and/or replication fork integrity. Hydroxyurea (HU) stalls replication forks and targets cells with existing replicative stress by inhibiting deoxyribonucleotide production and delaying replicative DNA polymerase progression (Zeman and Cimprich, 2014). We exposed 293-A3Bp53 cells to $50 \mu \mathrm{M} \mathrm{HU}$ and found that APOBEC3B expression caused a fourfold increase in the sensitivity to $\mathrm{HU}$ (Figure 3A; $P<0.0001$, two-sided Student's $t$-test). We also found that induction of APOBEC3B in 293-A3B-p53 cells caused sensitivity to previously validated small-molecule inhibitors of either ATR (VX-970 (Hall et al, 2014) or AZD6738 (O'Connor, 2015), CHEK1 (SAR020106 (Walton et al, 2010)), WEE1 (AZD1775 (O'Connor, 2015)) or CHEK2 (CCT241533 (Anderson et al, 2011)) (Figures 3B-F, ANOVA $P<0.0001$ in each case). We also titrated doxinduced $A P O B E C 3 B$ expression and confirmed that even lesser degrees of induction of APOBEC3B expression caused sensitivity to the CHEK2 inhibitor CCT241533 (1-1000 $\mathrm{ng} \mathrm{ml}^{-1}$ dox; Figure 3G; ANOVA $P<0.0001$ in each case). Many clinical PARP inhibitors cause cytotoxicity by 'trapping' PARP1 on DNA (Murai et al, 2012; Pettitt et al, 2013; Hopkins et al, 2015), an effect that likely impairs the progress of replication forks. We found that the expression of APOBEC $3 \mathrm{~B}$ caused moderate sensitisation to two chemically distinct clinical PARP inhibitors, olaparib (Figure 4A; ANOVA $P<0.0001$ ) and talazoparib (aka BMN 673, Figure 4B; ANOVA $P<0.0001)$.

We next assessed whether drug combination strategies designed to target cells with replicative stress might also selectively target cells with elevated APOBEC3B expression. To do this, we assessed whether elevated APOBEC3B might sensitise cells to a platinum salt, cisplatin used in combination with an ATR inhibitor (Wang et al, 2012) or a PARP inhibitor used in combination with either an ATR or WEE1 inhibitor. We found that cells with induced APOBEC3B expression exhibited an enhanced level of sensitivity to each of these combinations. For example, the induction of
APOBEC3B caused a $>4000$-fold increase in the sensitivity to a cisplatin/ATR inhibitor combination (Figures 5A and B; ANOVA $P<0.0001$ in each case), $>40000$-fold increase in the sensitivity to an ATR/PARP inhibitor combination (Figure 5C; ANOVA $P<0.0001$ in each case) and 148 -fold change in the sensitivity to PARP inhibitor/WEE1 inhibitor combination (Figure 5D; ANOVA $P<0.0001$ in each case). The profound sensitivity to the ATR/ PARP inhibitor combination caused by APOBEC3B expression in 293-A3B-p53 cells led us to assess this combination in HCC1143 breast tumour cells, which exhibit a high level of APOBEC3B expression (Supplementary Figure S8). Compared with nontumour breast epithelial MCF10A cells, HCC1143 cells were significantly more sensitive to ATR/PARP inhibitor combination (Supplementary Figure S9; ANOVA $P<0.001$ in each case). We do note, however, that although APOBEC3B expression was significantly elevated in HCC1143 cells compared with MCF10A cells (Supplementary Figure S8), factors other than APOBEC3B expression might explain the differences in ATR/PARP inhibitor sensitivity. Taken together, our observations suggested that elevated APOBEC3B expression might cause vulnerabilities in tumour cells that can be exploited by drugs targeting DDR kinase enzymes.

\section{DISCUSSION}

Here we show that the proliferative defects imparted upon a cell by high-level APOBEC3B expression can be abrogated by inactivation of $\mathrm{p} 53$. It seems reasonable to suggest that this might explain why cancers with high levels of APOBEC3B expression and/or an APOBEC3-mutational signature frequently exhibit TP53 mutations (Burns et al, 2013a; Henderson et al, 2014; Silwal-Pandit et al, 2014). We also show that once the $\mathrm{G}_{2} / \mathrm{M}$ cell cycle arrest caused by elevated APOBEC $3 \mathrm{~B}$ is reversed via loss of $\mathrm{p} 53$, cells with prolonged APOBEC 3B expression develop a kataegic mutational signature. Akre et al (2016) recently described the mutational consequences of intermittently induced APOBEC 3B expression in 293 cells with active p53, rather than continuously expressed $\mathrm{APOBEC} 3 \mathrm{~B}$ in $\mathrm{p} 53$-defective 293-A3B-p53 cells, described here. In 293-A3B cells, Akre et al (2016) found that intermittent APOBEC3B expression caused an increase in C-to-T mutations in TCG motifs and an increase in the frequency of mutations at A/T base pairs. These observations are consistent with the hypothesis that genomic uracil residues caused by APOBEC3B activity might be repaired by error-prone, and thus mutation-inducing, processes. Furthermore, Akre et al (2016) found an enrichment for C-to-G mutations within TCW motifs in cells with intermittent APOBEC3B expression. Each of these observations are consistent with the mutational spectrum we observed in 293-A3B-p53 cells with induced APOBEC3B expression, notably the increase in $\mathrm{C}$ residue mutations within TCW motifs (Figure 2, Supplementary Figures S4-S7). In our 293-A3B-p53 cells with chronic APOBEC3B expression, we observed an increase in a kataegic mutational pattern, with a ninefold increase in clustered mutations (IMD $\leq 1000 \mathrm{bp}$ ), the majority of these being C-to-T transitions (Figure 2, Supplementary Figure S4). In comparison, while pulsed APOBEC3B expression in 293-A3B cells clearly caused an increase in mutations likely caused by APOBEC3B, the kataegic clustering of mutations was not as profound. It is possible that this difference might be due to the loss of p53 in 293-A3B cells, with the loss of p53 either allowing cells to tolerate clustered mutations or the processes that cause these. However, we also note that there are important differences in experimental design in the work described in Figure 2, compared with the experiments described in Akre et al (2016) that might also 
explain the somewhat distinct mutational profiles. For example, in Akre et al (2016), the mutational spectrum in cells was assessed after 10 rounds of dox exposure; in the work presented here, we describe mutational consequences after continuous 14-day dox exposure.

Despite the proliferative capacity of p53-inactivated cells, we also found that p53-defective cells with elevated APOBEC3B expression are vulnerable to small-molecule DDR inhibitors, including ATR, WEE1, CHEK1 and CHEK2 inhibitors. The CHEK1 inhibitor sensitivity caused by APOBEC3B expression seen in this work is consistent with a correlation between APOBEC3B mRNA expression and sensitivity to the CHEK1 inhibitor CCT244747 in tumour cell lines, observed elsewhere (Kanu et al, 2016). The most notable drug vulnerabilities associated with APOBEC3B expression were DDR inhibitor combinations, including a combination of ATR plus PARP inhibitor now being assessed clinically (NCT02264678).

One simple model to explain our observations is that, while p53 inactivation allows cells to proliferate in the face of high-level APOBEC3B expression, APOBEC3B still causes a form of DNA damage, which under certain conditions such as the presence of DDR inhibitors might impair the fitness of cells. It seems possible that the $\gamma \mathrm{H} 2 \mathrm{AX}$ and RPA phosphorylation we observe in cells with elevated APOBEC3B, both when cells are p53 proficient or p53 defective (Figure 1), is indicative of replication fork stress caused by the excessive APOBEC3B activity, possibly on lagging strand DNA (Hoopes et al, 2016). Recent work has suggested that APOBEC3B activity is induced by replication fork stress (Kanu et al, 2016); our work suggests that APOBEC3B expression/activity might also contribute to replication fork stress as well as being caused by it. Replication fork stress, especially in the absence of p53 function, might generate an enhanced reliance upon DNA repair kinases such as ATR and CHEK1 that instigate signalling cascades that stabilise and repair replication forks, as well as inhibiting of processes such as new fork origin firing or the further accumulation of ssDNA that would otherwise exacerbate replication fork stress (Shechter et al, 2004; Petermann et al, 2010). This reliance on DNA repair kinases might extend to WEE1 and CHEK2, given their roles in preventing premature entry through the cell cycle in the face of a deleterious level of DNA damage (O'Connell et al, 1997; Reinhardt and Yaffe, 2009).

Whether these DNA repair kinase vulnerabilities extend to human tumours with elevated APOBEC3B expression remains to be seen, but we note that some of the inhibitors we describe here are already undergoing clinical trial assessment, including the ATR inhibitors AZD6738 (e.g., clinical trial identifiers NCT01955668, NCT02223923, NCT02264678), VX970 (NCT02567409, NCT02487095, NCT02567422) and the WEE1 inhibitor AZD1775 (e.g., NCT01164995 and others summarised in O'Connor, 2015), suggesting that retrospectively assessing tumoural APOBEC3B expression in these trials might be worthwhile. We also note that, although we have identified DDR inhibitor vulnerabilities associated with high-level APOBEC3B expression in 293-A3B-p53 cells, subsequent validation is required to extend these observations and to optimise how DDR inhibitors might be used to deliver profound, long-lasting antitumour responses in a significant proportion of patients with tumours with elevated APOBEC3B expression. Such a validation process might involve modulating APOBEC3B levels in relatively large panels of tumour cell lines and in in vivo models of cancer and then assessing drug sensitivity. Given the central role of p53 in controlling the cell cycle and DDR, it is also possible that the lack of p53 in 293-A3B-p53 cells influences some of the DDR inhibitors responses we have observed; it remains to be seen whether tumour cells without p53 dysfunction but which tolerate high-level APOBEC3B expression by other means also exhibit similar drug sensitivities.

\section{ACKNOWLEDGEMENTS}

This work was supported by EMBO, CRUK Programme Grant A14276 and Breast Cancer Now, ICGEB CRP/HUN14-01 and National Research, Development and Innovation Office (Hungary) grants K119493 and K109486. JN was a recipient of an EMBO Long Term Fellowship. We also acknowledge NHS funding to the Royal Marsden NIHR Biomedical Research Centre. RSH is an Investigator of the Howard Hughes Medical Institute.

${ }^{6}$ Current address: UCSF Helen Diller Family Comprehensive Cancer Centre, San Francisco, California 94158, USA.

\section{CONFLICT OF INTEREST}

RSH is a co-founder, shareholder and consultant of ApoGen Biotechnologies, Inc. CJL and AA are inventors on patents describing the use of PARP inhibitors and stand to gain from their development as part of the ICR, 'Rewards to Inventors', scheme. All authors have read and approved the final draft of the manuscript.

\section{AUTHOR CONTRIBUTIONS}

JN, RH, BGV, AA and CJL designed the experiments. AA and CJL supervised the work. JN conducted the experiments and drafted the manuscript with the supervision of SJP and CJL. In addition, IB carried out western blotting experiments; JC and RK conducted WGS analysis; IS, NK and BGV carried out genomic uracil DNA experiments; RSH, AAS and VM carried out p53 CRISPR-Cas9 experiments and FW carried out FACS experiments.

\section{REFERENCES}

Akre MK, Starrett GJ, Quist JS, Temiz NA, Carpenter MA, Tutt AN, Grigoriadis A, Harris RS (2016) Mutation processes in 293-based clones overexpressing the DNA cytosine deaminase APOBEC3B. PLoS One 11: e0155391.

Alexandrov LB, Nik-Zainal S, Wedge DC, Aparicio SA, Behjati S, Biankin AV, Bignell GR, Bolli N, Borg A, Borresen-Dale AL, Boyault S, Burkhardt B, Butler AP, Caldas C, Davies HR, Desmedt C, Eils R, Eyfjord JE, Foekens JA, Greaves M, Hosoda F, Hutter B, Ilicic T, Imbeaud S, Imielinski M, Jager N, Jones DT, Jones D, Knappskog S, Kool M, Lakhani SR, Lopez-Otin C, Martin S, Munshi NC, Nakamura H, Northcott PA, Pajic M, Papaemmanuil E, Paradiso A, Pearson JV, Puente XS, Raine K, Ramakrishna M, Richardson AL, Richter J, Rosenstiel P, Schlesner M, Schumacher TN, Span PN, Teague JW, Totoki Y, Tutt AN, Valdes-Mas R, van Buuren MM, van 't Veer L, Vincent-Salomon A, Waddell N, Yates LR, Zucman-Rossi J, Futreal PA, McDermott U, Lichter P, Meyerson M, Grimmond SM, Siebert R, Campo E, Shibata T, Pfister SM, Campbell PJ, Stratton MR (2013) Signatures of mutational processes in human cancer. Nature 500: 415-421. Anderson BD, Harris RS (2015) Transcriptional regulation of APOBEC3 antiviral immunity through the CBF- $\beta /$ RUNX axis. Sci $A d v$ 1: e1500296.

Anderson VE, Walton MI, Eve PD, Boxall KJ, Antoni L, Caldwell JJ, Aherne W, Pearl LH, Oliver AW, Collins I, Garrett MD (2011) CCT241533 is a potent and selective inhibitor of CHK2 that potentiates the cytotoxicity of PARP inhibitors. Cancer Res 71: 463-472.

Bhagwat AS, Hao W, Townes JP, Lee H, Tang H, Foster PL (2016) Strand-biased cytosine deamination at the replication fork causes cytosine to thymine mutations in Escherichia coli. Proc Natl Acad Sci USA 113: 2176-2181.

Burns MB, Lackey L, Carpenter MA, Rathore A, Land AM, Leonard B, Refsland EW, Kotandeniya D, Tretyakova N, Nikas JB, Yee D, Temiz NA, Donohue DE, McDougle RM, Brown WL, Law EK, Harris RS (2013a) APOBEC3B is an enzymatic source of mutation in breast cancer. Nature 494: $366-370$ 
Burns MB, Leonard B, Harris RS (2015) APOBEC3B: pathological consequences of an innate immune DNA mutator. Biomed J 38: 102-110.

Burns MB, Temiz NA, Harris RS (2013b) Evidence for APOBEC3B mutagenesis in multiple human cancers. Nat Genet 45: 977-983.

Chan K, Gordenin DA (2015) Clusters of multiple mutations: incidence and molecular mechanisms. Annu Rev Genet 49: 243-267.

Conticello SG (2008) The AID/APOBEC family of nucleic acid mutators. Genome Biol 9: 229.

Ding Q, Chang CJ, Xie X, Xia W, Yang JY, Wang SC, Wang Y, Xia J, Chen L, Cai C, Li H, Yen CJ, Kuo HP, Lee DF, Lang J, Huo L, Cheng X, Chen YJ, Li CW, Jeng LB, Hsu JL, Li LY, Tan A, Curley SA, Ellis LM, Dubois RN, Hung MC (2011) APOBEC3G promotes liver metastasis in an orthotopic mouse model of colorectal cancer and predicts human hepatic metastasis. J Clin Invest 121: 4526-4536.

Drier Y, Lawrence MS, Carter SL, Stewart C, Gabriel SB, Lander ES, Meyerson M, Beroukhim R, Getz G (2013) Somatic rearrangements across cancer reveal classes of samples with distinct patterns of DNA breakage and rearrangement-induced hypermutability. Genome Res 23: 228-235.

Hall AB, Newsome D, Wang Y, Boucher DM, Eustace B, Gu Y, Hare B, Johnson MA, Milton S, Murphy CE, Takemoto D, Tolman C, Wood M, Charlton P, Charrier JD, Furey B, Golec J, Reaper PM, Pollard JR (2014) Potentiation of tumor responses to DNA damaging therapy by the selective ATR inhibitor VX-970. Oncotarget 5: 5674-5685.

Haradhvala NJ, Polak P, Stojanov P, Covington KR, Shinbrot E, Hess JM, Rheinbay E, Kim J, Maruvka YE, Braunstein LZ, Kamburov A, Hanawalt PC, Wheeler DA, Koren A, Lawrence MS, Getz G (2016) Mutational strand asymmetries in cancer genomes reveal mechanisms of DNA damage and repair. Cell 164: 538-549.

Harris RS, Liddament MT (2004) Retroviral restriction by APOBEC proteins. Nat Rev Immunol 4: 868-877.

Helleday T, Eshtad S, Nik-Zainal S (2014) Mechanisms underlying mutational signatures in human cancers. Nat Rev Genet 15: 585-598.

Henderson S, Chakravarthy A, Su X, Boshoff C, Fenton TR (2014) APOBECmediated cytosine deamination links PIK3CA helical domain mutations to human papillomavirus-driven tumor development. Cell Rep 7: 1833-1841.

Hoopes JI, Cortez LM, Mertz TM, Malc EP, Mieczkowski PA, Roberts SA (2016) APOBEC3A and APOBEC3B preferentially deaminate the lagging strand template during DNA replication. Cell Rep 14: 1273-1282.

Hopkins TA, Shi Y, Rodriguez LE, Solomon LR, Donawho CK, DiGiammarino EL, Panchal SC, Wilsbacher JL, Gao W, Olson AM, Stolarik DF, Osterling DJ, Johnson EF, Maag D (2015) Mechanistic dissection of PARP1 trapping and the impact on in vivo tolerability and efficacy of PARP inhibitors. Mol Cancer Res 13: 1465-1477.

Jarmuz A, Chester A, Bayliss J, Gisbourne J, Dunham I, Scott J, Navaratnam N (2002) An anthropoid-specific locus of orphan C to U RNA-editing enzymes on chromosome 22. Genomics 79: 285-296.

Kanu N, Cerone MA, Goh G, Zalmas LP, Bartkova J, Dietzen M, McGranahan N, Rogers R, Law EK, Gromova I, Kschischo M, Walton MI, Rossanese OW, Bartek J, Harris RS, Venkatesan S, Swanton C (2016) DNA replication stress mediates APOBEC3 family mutagenesis in breast cancer. Genome Biol 17: 185.

Kaufmann SH, Desnoyers S, Ottaviano Y, Davidson NE, Poirier GG (1993) Specific proteolytic cleavage of poly(ADP-ribose) polymerase: an early marker of chemotherapy-induced apoptosis. Cancer Res 53: 3976-3985.

Lackey L, Law EK, Brown WL, Harris RS (2013) Subcellular localization of the APOBEC3 proteins during mitosis and implications for genomic DNA deamination. Cell Cycle 12: 762-772.

Lakin ND, Hann BC, Jackson SP (1999) The ataxia-telangiectasia related protein ATR mediates DNA-dependent phosphorylation of p53. Oncogene 18: 3989-3995.

Leonard B, Hart SN, Burns MB, Carpenter MA, Temiz NA, Rathore A, Vogel RI, Nikas JB, Law EK, Brown WL, Li Y, Zhang Y, Maurer MJ, Oberg AL, Cunningham JM, Shridhar V, Bell DA, April C, Bentley D, Bibikova M, Cheetham RK, Fan JB, Grocock R, Humphray S, Kingsbury Z, Peden J, Chien J, Swisher EM, Hartmann LC, Kalli KR, Goode EL, Sicotte H, Kaufmann SH, Harris RS (2013) APOBEC3B upregulation and genomic mutation patterns in serous ovarian carcinoma. Cancer Res 73: 7222-7231.

Leonard B, McCann JL, Starrett GJ, Kosyakovsky L, Luengas EM, Molan AM, Burns MB, McDougle RM, Parker PJ, Brown WL, Harris RS (2015) The $\mathrm{PKC} / \mathrm{NF}-\mathrm{kappaB}$ signaling pathway induces APOBEC3B expression in multiple human cancers. Cancer Res 75: 4538-4547.
Murai J, Huang SN, Das BB, Renaud A, Zhang Y, Doroshow JH, Ji J, Takeda S, Pommier Y (2012) Differential trapping of PARP1 and PARP2 by clinical PARP inhibitors. Cancer Res 72: 5588-5599.

Nik-Zainal S, Alexandrov LB, Wedge DC, Van Loo P, Greenman CD, Raine K, Jones D, Hinton J, Marshall J, Stebbings LA, Menzies A, Martin S, Leung K, Chen L, Leroy C, Ramakrishna M, Rance R, Lau KW, Mudie LJ, Varela I, McBride DJ, Bignell GR, Cooke SL, Shlien A, Gamble J, Whitmore I, Maddison M, Tarpey PS, Davies HR, Papaemmanuil E, Stephens PJ, McLaren S, Butler AP, Teague JW, Jonsson G, Garber JE, Silver D, Miron P, Fatima A, Boyault S, Langerod A, Tutt A, Martens JW, Aparicio SA, Borg A, Salomon AV, Thomas G, Borresen-Dale AL, Richardson AL, Neuberger MS, Futreal PA, Campbell PJ, Stratton MR. Breast Cancer Working Group of the International Cancer Genome Consortium (2012a) Mutational processes molding the genomes of 21 breast cancers. Cell 149: 979-993.

Nik-Zainal S, Van Loo P, Wedge DC, Alexandrov LB, Greenman CD, Lau KW, Raine K, Jones D, Marshall J, Ramakrishna M, Shlien A, Cooke SL, Hinton J, Menzies A, Stebbings LA, Leroy C, Jia M, Rance R, Mudie LJ, Gamble SJ, Stephens PJ, McLaren S, Tarpey PS, Papaemmanuil E, Davies HR, Varela I, McBride DJ, Bignell GR, Leung K, Butler AP, Teague JW, Martin S, Jonsson G, Mariani O, Boyault S, Miron P, Fatima A, Langerod A, Aparicio SA, Tutt A, Sieuwerts AM, Borg A, Thomas G, Salomon AV, Richardson AL, Borresen-Dale AL, Futreal PA, Stratton MR, Campbell PJ (2012b) The life history of 21 breast cancers. Cell 149: 994-1007.

O'Connell MJ, Raleigh JM, Verkade HM, Nurse P (1997) Chk1 is a wee1 kinase in the G2 DNA damage checkpoint inhibiting cdc2 by Y15 phosphorylation. EMBO J 16: 545-554.

O'Connor MJ (2015) Targeting the DNA damage response in cancer. Mol Cell 60: $547-560$.

Ohba K, Ichiyama K, Yajima M, Gemma N, Nikaido M, Wu Q, Chong P, Mori S, Yamamoto R, Wong JE, Yamamoto N (2014) In vivo and in vitro studies suggest a possible involvement of HPV infection in the early stage of breast carcinogenesis via APOBEC3B induction. PLoS One 9: e97787.

Petermann E, Woodcock M, Helleday T (2010) Chk1 promotes replication fork progression by controlling replication initiation. Proc Natl Acad Sci USA 107: 16090-16095.

Pettitt SJ, Rehman FL, Bajrami I, Brough R, Wallberg F, Kozarewa I, Fenwick K, Assiotis I, Chen L, Campbell J, Lord CJ, Ashworth A (2013) A genetic screen using the PiggyBac transposon in haploid cells identifies Parp1 as a mediator of olaparib toxicity. PLoS One 8: e61520.

Rebhandl S, Huemer M, Gassner FJ, Zaborsky N, Hebenstreit D, Catakovic K, Grossinger EM, Greil R, Geisberger R (2014) APOBEC3 signature mutations in chronic lymphocytic leukemia. Leukemia 28: 1929-1932.

Reinhardt HC, Yaffe MB (2009) Kinases that control the cell cycle in response to DNA damage: Chk1, Chk2, and MK2. Curr Opin Cell Biol 21: $245-255$

Roberts SA, Sterling J, Thompson C, Harris S, Mav D, Shah R, Klimczak LJ, Kryukov GV, Malc E, Mieczkowski PA, Resnick MA, Gordenin DA (2012) Clustered mutations in yeast and in human cancers can arise from damaged long single-strand DNA regions. Mol Cell 46: 424-435.

Rona G, Scheer I, Nagy K, Palinkas HL, Tihanyi G, Borsos M, Bekesi A, Vertessy BG (2016) Detection of uracil within DNA using a sensitive labeling method for in vitro and cellular applications. Nucleic Acids Res 44: e28.

Sanjana NE, Shalem O, Zhang F (2014) Improved vectors and genome-wide libraries for CRISPR screening. Nat Methods 11: 783-784.

Saraconi G, Severi F, Sala C, Mattiuz G, Conticello SG (2014) The RNA editing enzyme APOBEC1 induces somatic mutations and a compatible mutational signature is present in esophageal adenocarcinomas. Genome Biol 15: 417.

Seplyarskiy VB, Soldatov RA, Popadin KY, Antonarakis SE, Bazykin GA, Nikolaev SI (2016) APOBEC-induced mutations in human cancers are strongly enriched on the lagging DNA strand during replication. Genome Res 26: 174-182.

Shechter D, Costanzo V, Gautier J (2004) ATR and ATM regulate the timing of DNA replication origin firing. Nat Cell Biol 6: 648-655.

Silwal-Pandit L, Vollan HK, Chin SF, Rueda OM, McKinney S, Osako T, Quigley DA, Kristensen VN, Aparicio S, Borresen-Dale AL, Caldas C, Langerod A (2014) TP53 mutation spectrum in breast cancer is subtype specific and has distinct prognostic relevance. Clin Cancer Res 20: 3569-3580. 
Simonelli V, Narciso L, Dogliotti E, Fortini P (2005) Base excision repair intermediates are mutagenic in mammalian cells. Nucleic Acids Res 33: 4404-4411.

Swanton C, McGranahan N, Starrett GJ, Harris RS (2015) APOBEC enzymes: mutagenic fuel for cancer evolution and heterogeneity. Cancer Discov 5: 704-712.

Taylor BJ, Nik-Zainal S, Wu YL, Stebbings LA, Raine K, Campbell PJ, Rada C, Stratton MR, Neuberger MS (2013) DNA deaminases induce break-associated mutation showers with implication of APOBEC3B and 3A in breast cancer kataegis. Elife 2: e00534.

The Cancer Genome Atlas Research Network (2014) Comprehensive molecular characterization of urothelial bladder carcinoma. Nature 507: 315-322.

Tibbetts RS, Brumbaugh KM, Williams JM, Sarkaria JN, Cliby WA, Shieh SY, Taya Y, Prives C, Abraham RT (1999) A role for ATR in the DNA damage-induced phosphorylation of p53. Genes Dev 13: 152-157.

Verhalen B, Starrett GJ, Harris RS, Jiang M (2016) Functional upregulation of the DNA cytosine deaminase APOBEC3B by polyomaviruses. J Virol 90: 6379-6386.

Vieira VC, Leonard B, White EA, Starrett GJ, Temiz NA, Lorenz LD, Lee D, Soares MA, Lambert PF, Howley PM, Harris RS (2014) Human papillomavirus E6 triggers upregulation of the antiviral and cancer genomic DNA deaminase APOBEC3B. MBio 5: e02234-14.
Walton MI, Eve PD, Hayes A, Valenti M, De Haven Brandon A, Box G, Boxall KJ, Aherne GW, Eccles SA, Raynaud FI, Williams DH, Reader JC, Collins I, Garrett MD (2010) The preclinical pharmacology and therapeutic activity of the novel CHK1 inhibitor SAR-020106. Mol Cancer Ther 9: 89-100.

Wang HC, Lee AY, Chou WC, Wu CC, Tseng CN, Liu KY, Lin WL, Chang FR, Chuang DW, Hunyadi A, Wu YC (2012) Inhibition of ATR-dependent signaling by protoapigenone and its derivative sensitizes cancer cells to interstrand cross-link-generating agents in vitro and in vivo. Mol Cancer Ther 11: 1443-1453.

Zeman MK, Cimprich KA (2014) Causes and consequences of replication stress. Nat Cell Biol 16: 2-9.

(c) (i) (2) This work is licensed under the Creative Commons (c) ${ }_{\text {BY NC SA }}$ Attribution-Non-Commercial-Share Alike 4.0 International License. To view a copy of this license, visit http:// creativecommons.org/licenses/by-nc-sa/4.0/

(C) The Author(s) named above 2017

Supplementary Information accompanies this paper on British Journal of Cancer website (http://www.nature.com/bjc) 